UCRL. 88055

PREPRINT

CCNF $-821089-8$

Observations of Parametric Instabilities

In Lorig-Scalelength Plasmas

\author{
E.M. Campbel \}, C.E. Max, D.W. Phillion, \\ R.E. Turner, K. Estabrook, B. Laskinski, \\ W.L. Kruer, and H.C. Mead
}

This paper was prepared for submittal to the

Sixth Workshop on Laser Interaction and

Related Plasma Phenomena, Monterey, California, Octcber, 1982.

March 22, 1983

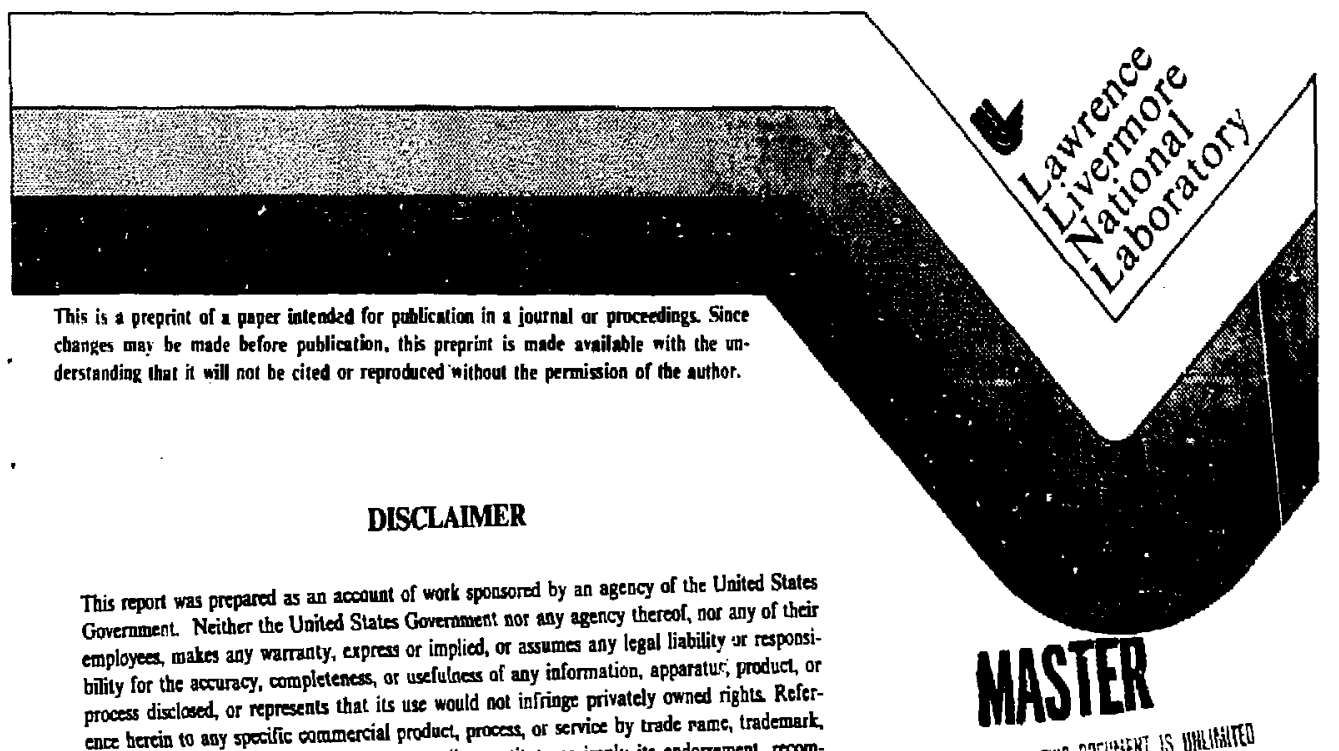
ence herein to asy specific commercial product, process, or service by trade rame, trademark, manofacturer, or otherwise does nol necesesrily constitute or imply its endorsement, teommendation, or favoring by the United States Government of any agency thereol. The views and opinions of authors expressed berein do oot aecessarily state or reflect those of the

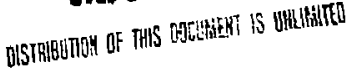
United States Government or any agency thereof. 


\section{OBSERVATIONS OF PARAMETRIC INSTABILITIES}

IN LONG-SCALELENGTH PLASMAS

E. M. Cimpbell, C. E. Max, D. W. Phillion, R. E. Turner, K, Estabrook, B.i.lasinski, W. L. Kruer, \& W. C. Mead

Laurence Livermore National Laburatory

Livermore, California 94550

\section{INTRODUCTION}

The role of laser wavelength in laser-plasma coupling physics has been extensively studied at many laboratories for the past several years. (1) These studies have been motivated by theoretical considerations, which indicate improved absorption, reduced supratienal electron.production, and increased hydrodynamic efficiencies for laser wavelengths $\leq 1 \mu \mathrm{m}$. (2) Indeed, while such improvements have been experimentally verified, the limited energy and power presently available $\left(E_{L} \leq 150\right.$ Joules, $P_{L} \leq 10^{l}(\mathrm{~W})$ have restricted the studies to plasma coronas of óimensions $\leqslant 100 \lambda_{0}$ $\left(\lambda_{0}\right.$ is the vacuum laser wavelength). Such small coronas are not characieristic of near-term and future ICF targets designed for ignition and gain. (3) These targets will have diameters greater than $1 \mathrm{~mm}$ and they will be irradiated with laser pulses of several nanosecond duration ( $3 \leqslant \tau_{L} \leqslant 10$ ns). ( 3 ) Thus the targets will be enveloped by underdense plasma coronas having dimensions of $10^{3}-10^{4}$ vacuum laser havelengths. In such plasmas, coupling processes, such as inverse bremsstrahlung, Stimulated Raman and Brillevin Scattering, two-plesmon decay, and filamentation (pondermotive and themal), should became important. (4) Many of these processes to date are unimportant due to the limited size coronas presently available in experiments. It is thus necessary to perform. scaling experiments in which not only the laser wavelength, but also" the corona dimensions are varied.

The interest in such a study can clearly be seen in Fig. 1, where we show the location of various experiments in the palameter space of $L / \lambda_{0}$ ( $L$ is the relevant gradient length in the corona) and $1 \lambda_{0}^{2}(I$ is the peak laser intensity). (5) Also shown in 


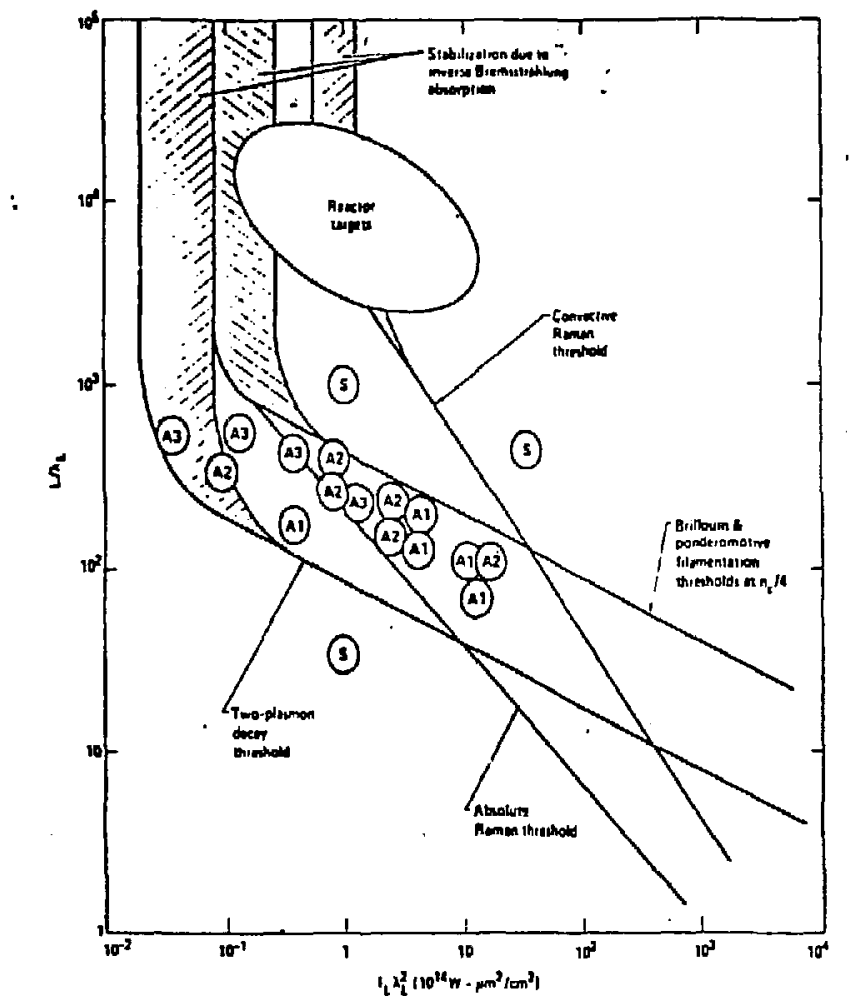

Fig. 1. Laser-plasma instability thresholds and present experimental irradiation conditions in $\mathrm{L} / \mathrm{A}_{0}$ and $I \lambda_{0}^{2}$ parameter space $\left(L, \lambda_{0}, I\right.$ are the coronal scale length, the vacuum laser wavelength, and peak laser intensity, respectively).

this figure are regions of this parameter space defined by the thresholds for many laser-plasma instabilities. For small $\mathrm{L} / \mathrm{h}_{0}$ and $h i g h ~ I \lambda_{0}^{2}$, these thresholds are detemined by gradient stabilization, whereas inverse bremsstrahlung completion determines the thresholds in the opposite limit of large $\mathrm{L} / \mathrm{h}_{\mathrm{o}}$ and $5 \mathrm{mall} \mathrm{I} h_{0}^{2}$. In viewing this figure, one should remember the lack of knowledge of both the details of the plasma conditions and the laser irradiation profile and the rigor of the threshold conditions themselves. As shown in this figure, the majority of experiments performed with $\lambda$ $\leq 1 \mu m$ to date fall below or do not lie far above any instability threshold which would pqtentially degrade absorption or praduce suprathermal electrons. (1) It is therefore not unexpected to find that, while evidence for processes such as Stimulated kaman 
Scattering and two-plasmon decay have clearly been observed in some ... 0.532 and $0.355 \mu m$ experiment.s, rhe inferred efficiencies af anch processes are very low, typicaliy measureo to be $210^{-4}$ to $10^{-5}$ of the incident laser energy. (6)

In this article we will discuss the experimental evidence for the influence of the coronal size on interaction physics. In particular we will emphasize results obtained at $\lambda_{L}=1.064 \mu \mathrm{m}$, since at present the only multi-kilojoule lasers available are at this wavelength. $(7)$ We will not discuss milti-kilojoule $\mathrm{CO}_{2}$ experiments, since both the long wavelength and the pondermotive force associated with these large $L_{0}^{2}$ experiments effectively limit the normalized corona dimensions $t o$ small or moderate dimensions $\left(\mathrm{L} / \mathrm{h}_{0}<10\right)$. (2)

This paper will be organized in the following manner. In the second section we discuss absorption; the dependence of scattered light signatures of parametric instabilities occurring at $n_{e} \leqslant n_{e} / 4$ on corona size is shown in section three; and evidence for suprathermal electron production in these long-scale length plasmas is presented in section four. The results and conclusions are finally sumarized in section five.

\section{ABSORPTION}

In early, high-intensity (I $\left.>10^{15} \mathrm{~W} / \mathrm{cm}^{2}\right)$, short polse $\left(T_{I}<50\right.$ psec), $1.064 \mathrm{\mu m}$ experiments, the dominant coupling mechanism was resonance absorption occurring rear a steepened, rippled, critical density surface. ( 8 ) This conclusion was inferred from a variety of experiments. ( 9 ) Absorption fractions were measured in the range of $30 \%$ to $40 \%$. (9) Such irradiation conditions, however, are not characteristic of that required for ablatively driven, high-performance implosions. (3) As experiments have evolved to irradiation conditions with longer pulse widths ( $\tau \geq 1 \mathrm{nsec}$ ) and nore moderate intensities $\left(1 \leq 10^{15} \mathrm{~W} / \mathrm{cm}^{2}\right)$, the presence of inverse bremstrahlung and an increased total absorption efficiency have been observed. In Fig. 2 we show the dependence of the absorption fraction of low-Z targets ( $\langle 2\rangle$ 2 3-6) for a fixed-peak incensity of $1-3 \times 10^{14}$ $\mathrm{W} / \mathrm{cm}^{2}$ as the laser pulse width (FWHM) is increased from 20.03 nsec to 23.0 nsec. In the experiments shown in this figure, the laser spot (and thus laser energy) was increased with the pulsewidth so as not to restrict the corona dimensions. Also shown in Fig. 2 is the expected absorption fraction due to inverse bremsstrahlung alone, using, a self-consistent planar, isothermal expansion coronal model.(10) The predictions of this model are in good agreement with sophisticated hydrodynamics codes, such as LASNEX. (11) The model does not include resonance absorption and thus underestimates the absorption for the short pulse experiments. While a clear increase in absorption is seen in the experiments with increasing pulsewidth, it is far less than would be expected if inverse brems- 


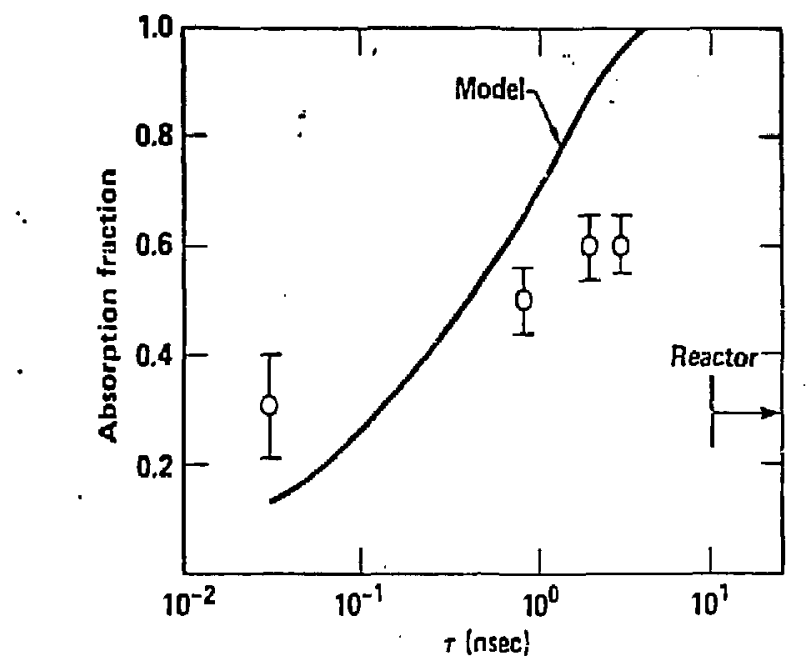

Fig. 2. Absorption of low-2 targets as a function of pulse width for an intensity of $1-3 \times 10^{14} \mathrm{H} / \mathrm{cm}^{2}$. Also shown is the predicted absorpioion due to inverse bremstrahlung.

strahlung were operative alone. Although a steepened profile and/or higher coronal temperature (such as would be caused by severe thermal transport inhibition) would help explain the data, the most likely explanation is the presence of Stimulated brillouin Scattering (SBS), particularly sidescatter. $(12\}$ Brillouin backscatter, enhanced with controlled prepulses, has been observed in small focal spot experiments, but in situations where the laser spot is large enough to maintain a one-dimensional expansion, SBS sidescatter appears to dominate.

Evidence for SBS sidescatter is shown in Figs. 3 and 4. Fig. 3 shows the dependence of the level of the light scattered out wi the plane of polarization (a characteristic signature of sidescatter) on the focal spot for Au disk targets irradiated at a fixed intensicy and pulse width of $23 \times 10^{14} \mathrm{~W} / \mathrm{cm}^{2}$ and $1 \mathrm{nsec}$, respectively. (12) In Fig. 4 we show the scattered Iight distribution from medium- and low-Z targets irradiated at a peak intensity of $1-2 \times 10^{14} \mathrm{~W} / \mathrm{cm}^{2}$, but. with widely varying laser conditions. (13) The broad angle scattering (curve a), observed with $3 \mathrm{nsec}, 1 \mathrm{~mm}$ experiments, is to be contrasted with the highly-peaked backscatter distributions seen in ioth short pulse ( $\tau$ q $0.1 \mathrm{nsec}$ ), large focal spot (Dia. $₹ 1 \mathrm{~mm}$ ) and long pulse ( $\tau$ \& 3 nsec), small focal spot (Dia. $<0.1 \mathrm{~mm}$ ) experiments. Also shown in the figure (curve $d$ ) is the scattered light distribution. caculated from a 2-D LASNEX simulation, which does not include SBS. 

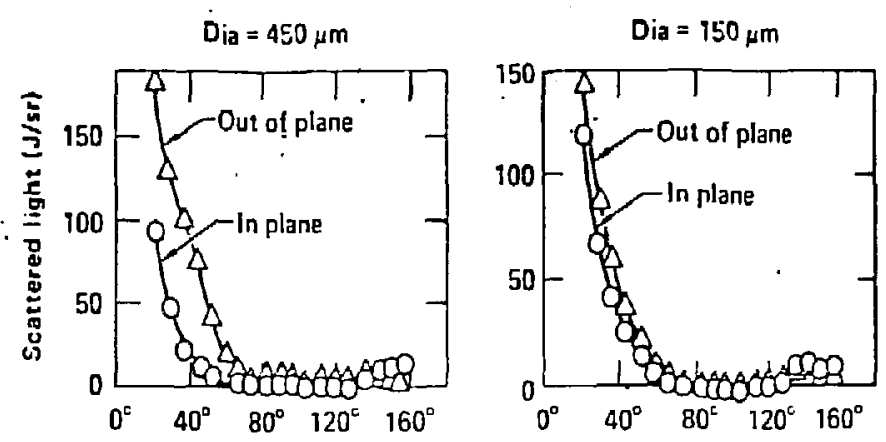

Polar angle, $\left.\theta 1^{\circ}\right)$

Fig. 3. Scattered light distribution from Au disk irradiated at I $23 \times 10^{14} \mathrm{~W} / \mathrm{cm}^{2}$ for a laser focal spot of $150 \mathrm{\mu m}$ and $450 \mathrm{~km}$.

\section{OPTICAL SIGNATURES OF PARAMETRIC INSTABILITIES}

Parametric instabilities, such as two-plasmon decay and Stimulated Raman Scattering (SRS) in which at least one of the decay modes is an electron plasma wave, are a serious concern for Inertial Fusion. (4) These high-frequency waves can heat electrons to iarge energies as they damp. These electrons can preheat the fuel lelectron range $\sim E^{1.5-2.0}$ ) and preveri the large fuel compressions that are required for high gain targets. The thresholds and efficiencies of these instabilities are strongly dependent on the homogeneity and dimensions of the corona. (4)

The scattered light directly or indirectly produced by these processes can provide information on the interaction physics occurring in the corona. For example, one of the daughter waves in the SRS interaction is an EM wave which can be readily measured. Quantitative analysis must still account for propagation through the plasma. Scattered light at $3 / 2 \omega_{0}$ can also indicate the presence of enhanced levels of electron plasma waves near $n_{c} / 4$. However, its generation is a secondary process (most likely produced by the combination of an EM wave and a plasmon) $(14)$ and is therefore much more difficult to quantitatively evaluate. In this section we will discuss the levels of the experimentally reasured scattered light and their dependence on the irradiation conditions, particularly the corona dimension.

In Fig. 5 we show the relative efficiency of the emission near $2 \lambda_{0}\left(\lambda_{s} 22.13 \mu \mathrm{m}\right)$ from high-z targets (Au and $\mathrm{Ti}$ ) as a function of the focal spot size for a fixed intensity and pulse width (I 2 $10^{15} \mathrm{~W} \mathrm{~cm}^{2}$ and $\left.\tau_{L} 2700-800 \mathrm{psec}\right)$. The measurements were made with an 


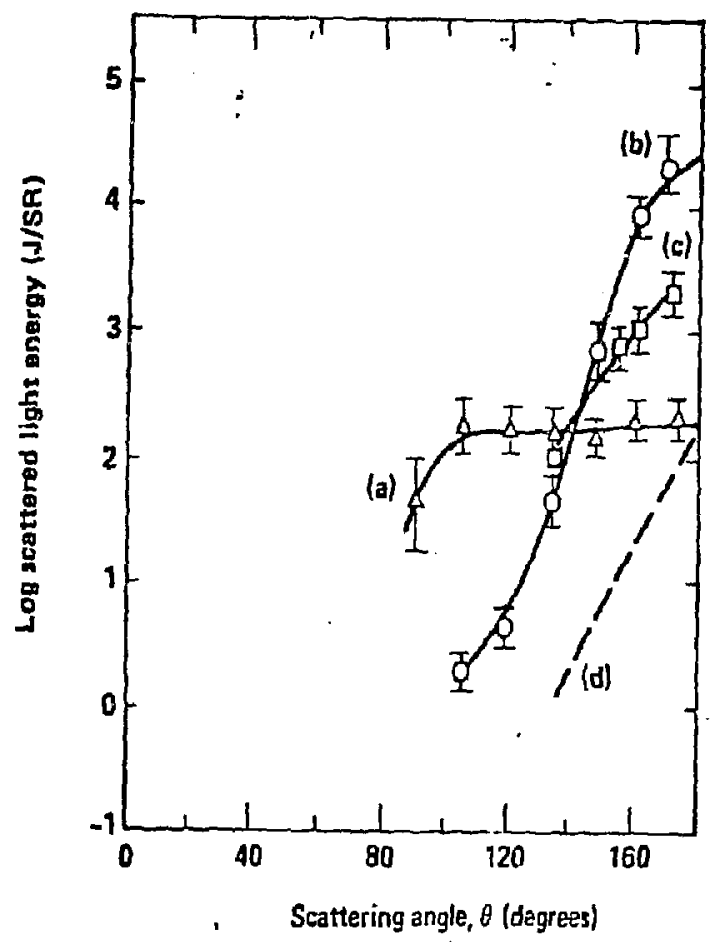

Fig. 4. Angular distribution of the scattered light from three experiments: a) $\mathrm{I}=10^{14} \mathrm{~W} / \mathrm{cm}^{2}, \mathrm{r}=3 \mathrm{nsec}$; spot dial. $=1000 \mathrm{un}$, carbon target;

i) $I=1-2 \times 10^{14} \mathrm{~W} / \mathrm{cm}^{2}, \tau=100 \mathrm{psec}$, spot dia. $=1000 \mu \mathrm{m}$, Fe target; c) $I=2.5 \times 10^{14} \mathrm{~W} / \mathrm{cm}^{2}, I=3 \mathrm{nsec}$, spot dia. $=75 \mu \mathrm{m}$, CH target; d) $2-D$ LASNEX predicted scattered light distribution for experimental condicions of Fig. la. The scattered light distribution are all normalized to $3 \mathrm{~kJ}$ incident energy.

array of InAs detectors, with a.2 $\mu \mathrm{m}$ FWHM bandpass filter, centered at $2.15 \mu \mathrm{m}$. This light is produced by either resonant SRS or inverse mode decay of an electron plasma wave near $n_{c} / 4$. The strong dependence on corona size (the pulse width is long enougi so that the focal spot limits the corona dimensions) is clearly seen in the figure. In addition, since the scattered light is produced near its critical surface, it can be highly absorbed as it exits through the plasma. For example, the inverse bremsstrahlung absorption length for an $n_{c} / 4$ plasma with $\langle 2\rangle \sim 40$ and $\mathrm{Te} \eta 7 \mathrm{keV}$ is $2120 \mathrm{\mu m}$. Absorption effects would be most severe in the largest foral spot experiments. 


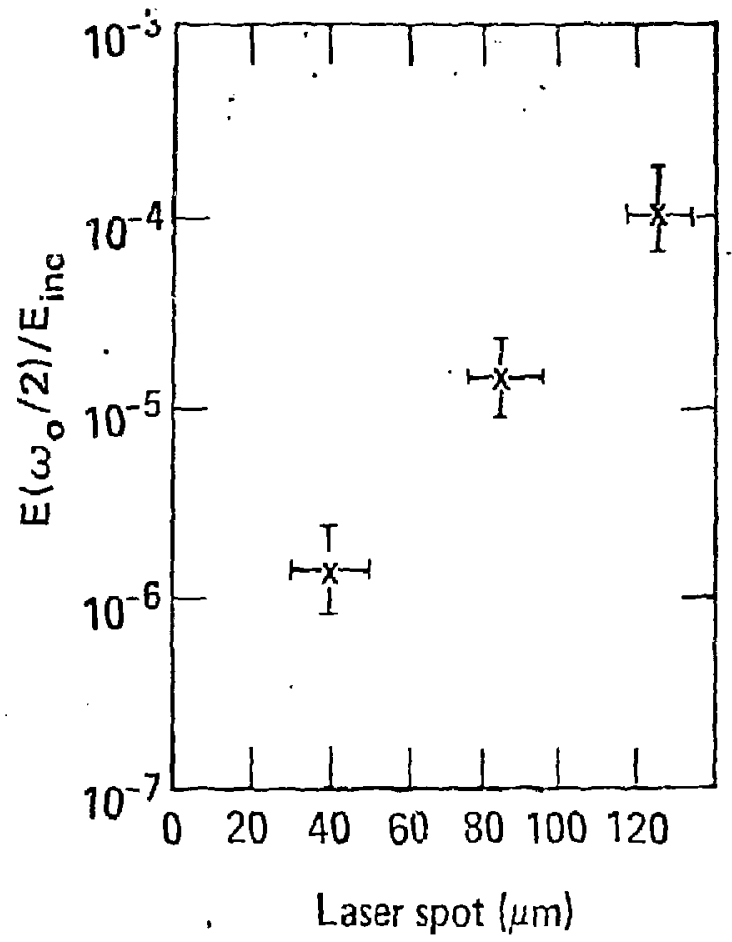

Fig. 5. Scattered light emission at $2 \lambda_{0}$ normalized by the laser energy as a function of the spot size for Au and Ti disks at a fixed intersity of $210^{15} \mathrm{~W} / \mathrm{cm}^{2}$ and pulse width of $700-800 \mathrm{psec}$.

Additional experiments, not described herein, have generally shown the SRS scattered light spertrum to be very broad. (15) The spectrum typically extends to wavelengths less than $1.5 \lambda_{0}$. This indicates that the convective SRS instabulity is occurring over a wide range of densities in the corona. The number of e-foldings that the SRS wave convectively grows is proportional to the electron density scalength and thus the measured scattered light from this instability should depend strongly on the corona size. In Fig. 5 we shaw the dependence of the $\$ k 5$ scattered light emitted at $1.8 \mathrm{jm}$ as a function of both intensity and pulsewidti from moderate- anò high $Z$ disk targets $\left(\mathrm{Ti}, \mathrm{Ni}, \mathrm{Au}_{\mathrm{u}}\right)$. (15) This light, borne far from its critical density, should not be greatly affected by absorption in the plasma. These measurements, obtained on the SHIVA laser, *ere performed with an absolutely calibrated InAs detector, filtered with a narrow band (Fwitu $\pi 0.08 \mathrm{jm}$ ) interference filter centered at $1.8 \mu_{\mathrm{m}}$. The data shown in Fig. 6 was obtained with a fixed spot size 


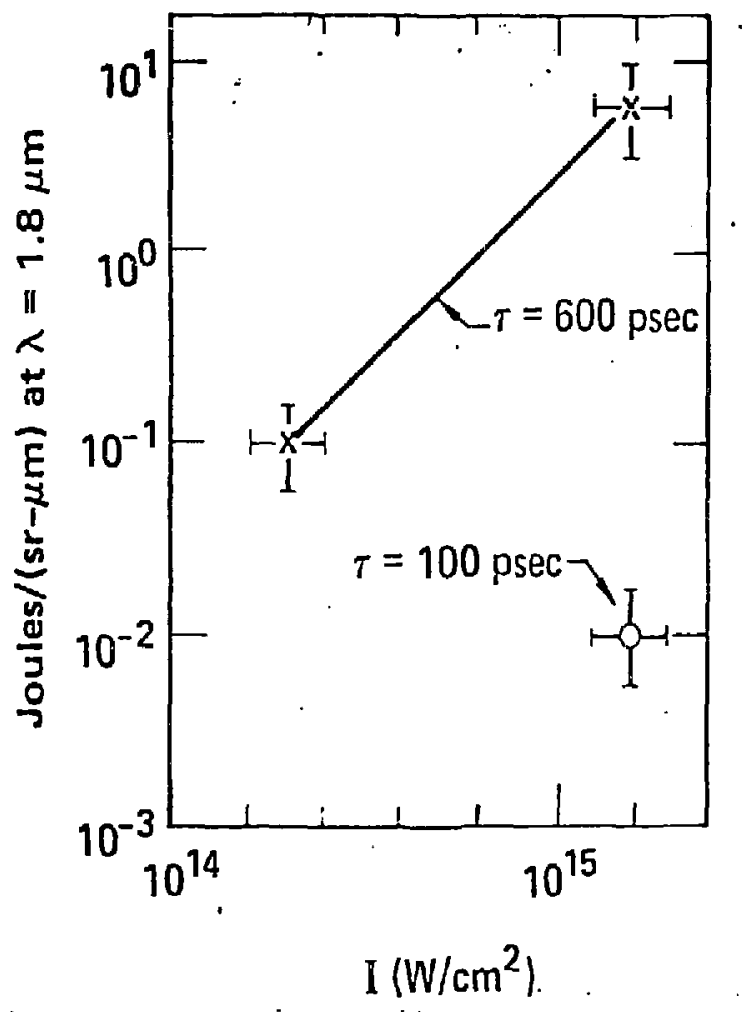

Fig. 6. Scattered light emission at $1.8 \mu$ as a function of both intensity and pulse width from $A u$ and Ni targets. The emission is nomalized to 480 Joules incidert. The focal spot is $600 \mu \mathrm{m}$ for all the experiments.

(Dia. $2500 \mu \mathrm{m}$ ) and the yield has been normalized to the same incident energy ( $E_{L} 2500$ Joules). The dependence on both the intensity and corona is clearly evidenced by the data. Some of the detected variation could be due to both changes in the angular dependence and scattered lighi spectrum, which would be emphasized in measurements made by a single detector with a narrow bandpass filter. Subsequent experimerts, however, do not support this. The indicated SRS yield, at the highest intensity shown in Fig. 6 , is approximately $21 \%$ of the incident laser energy.

The irradiation conditions utilized in these solid target experiments still do not produce the large, homogeneous coronas envisioned for future targets. One technique for creating more relevant plasmas is by the use of exploding thin foils. Such rargets are 
'designed to go underdense $\left(n_{e}<n_{c}\right)$ during the laser pulse. (16) in Fig. $7 a$ and $7 b$, we show a schematic representativa of such an experiment and the LASNEX calculated axial electron profile at the peak of the laser pulse ( $123 \times 10^{15} \mathrm{~W} / \mathrm{cm}^{2} ; \mathrm{T}^{2} .9 \mathrm{nsec}$ ). The foil has expanded to produce a nearly flat profile at $\pi_{c} / 4$ over dimensions of $:^{2}$ ?mm. Two-dimensional effects may somewhat limit the expansion, although 2-D calculations are in qualitative agreement with this result. The total amount of SRS light was measured by an array of light calorimeters filtered to accept light between $1.5 \mu \mathrm{m}$ and $2.5 \mu \mathrm{m}$. The angular distribution of the SRS light from the experiments shown in Fig. 7a is displayed in Fig. 8. Integrating over solid angle, the total energy in the strongly peaked distribution is $210 \%$ of the incident laser energy. Since the frequencies of the electron plasma wave and scattered light are similar, at least $20 \%$ of the laser energy participated in Stimulated Raman Scattering. Spectral measurements, discussed elsewhere ${ }^{(16)}$, show that since the scattering occurref near $n_{c} / 4$ and the foil relaxed to less than this density before the peak of the laser pulse, the instantaneous SRS efficiency may be as great as $50 \%$. In the following section, streak camera measurements which support this assertion will be discussed.
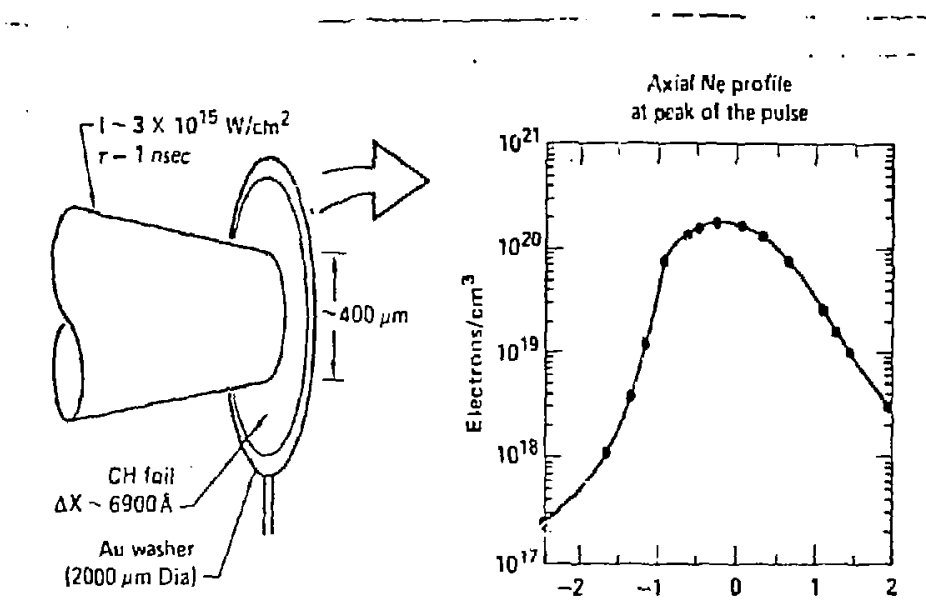

Fig. 7. a) Experimental set-up for thin foil experiment on SHIVA.

b) Axial electron density at the peak of the laser pulse for experiment shown in Fig. 7a.

The level of the detected $3 / 2 \omega_{0}$ light also depends strongly on the coronal dimensions. In Table 1 we list the $3 / 2 w_{0}$ efficiency measured by an array of appropriately filtered pin diodes seen on two experiments conducted on the. SHIVA facility. The experiments had similar irradiation conditions $(1000$ um diameter focal spot, 


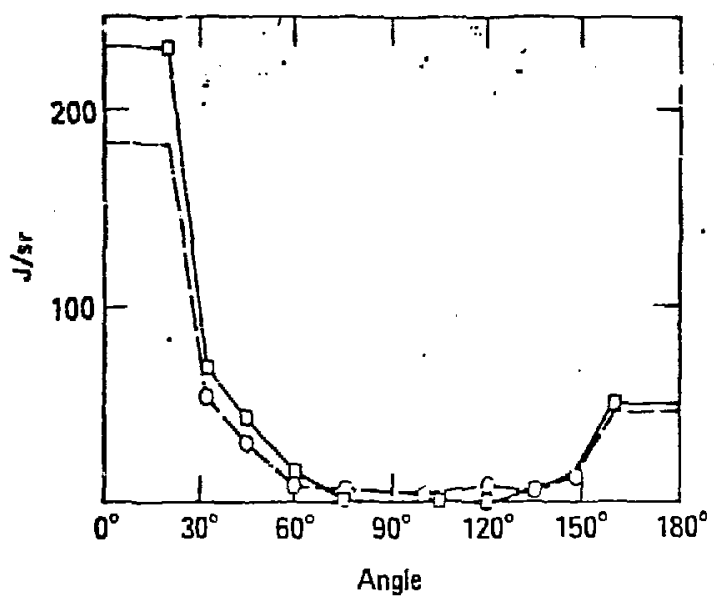

Fig. 8. Angular distribution of SRS light from the thin foil experiment described in Fig. 7a.

I ? $1-2 \times 10^{14} \mathrm{~W} / \mathrm{cm}^{2}$ ) except for the laser pulse duration. As seen in the table, the efficiency of the $3 / 2 w_{j}$ generation increased by approximately a factor of $10^{2}$ when the laser pulse was increased from 0.1 nsec' to 3 nsec. (13)

IABLE 1. $3 / 2 \omega_{0}$ Generation Efficiency

\begin{tabular}{lllll}
\hline Target & $\begin{array}{l}\text { Intensity } \\
\mathrm{W} / \mathrm{cm}^{2}\end{array}$ & $\begin{array}{l}\tau \\
\text { (nsec) }\end{array}$ & $\begin{array}{l}\text { Spot } \\
(\mu \mathrm{Nm})\end{array}$ & $E_{3 / 2 \omega_{0}} / E_{\mathrm{L}}$ \\
\hline $\mathrm{C}$ & $1 \times 10^{14}$ & 3 & 1000 & $4 \times 10^{-4}$ \\
$\mathrm{Fe}$ & $1-2 \times 10^{14}$ & 0.1 & 1000 & $3 \times 10^{-6}$
\end{tabular}

\section{SUPRATHERMAL ELECTRONS}

As we described in the last secticil, there exists a substantial amount of experimental evidence supporting the presence of laser-plasma instabilities occurring at $n_{e}<n_{c} / 4$ in large coronal plasmas. As mentioned previously, the fast electrons, produce: when the plasmons damp, are a major concern for laser-driven Inertial fusion. Simulations have shown that the characteristic. energy of these heated electrons can be approximated by $T_{H} 2 / / 2 \mathrm{~m} V_{0}^{2}$, 
where $V_{\psi}$ is the phase velocity of the electron plasma wave. For resonant SRS occurring at $n_{e} \eta_{c} / 4, T_{H}$ in excess of $100 \mathrm{keV}$ can resulc. (4) Because of the many processes which can produce suprathermal electrons; it is generally difficult to ascribe them to any particular instability sacurring in the plasma. One technique which potentially allows for some discrimination is time correlation of the high-energy bremsstrahlung produced by the suprathemals with characteristic optical signatures of the instabilities. In Fig. Y we show the results of an experiment using such a technique. The target was the explading foi $i$ discussed previously in section three of this paper. (16) In Fig. 9 we show the time histories of the diver L.054/um pulse, the $3 / 2 \omega_{0}$ smission from $n_{c} / 4$, and the $30-70 \mathrm{keV}$ $x$ ray emission produced in an Au ring upon which the thin foil was mounted. The $x$ ray and $3 / 2 \omega_{g}$ optical signatures are well correlated in time, both FWHM a:d time-of-peak emission. This result shows unambiguously that the major source of fast electrons in this experiment are processes cccuring at $n_{c} / 4$. Furthermore, the cut-off in the $3 / 2 w_{0}$ emission before the peak of the pulse supports the hydro calculations described in the previous section.

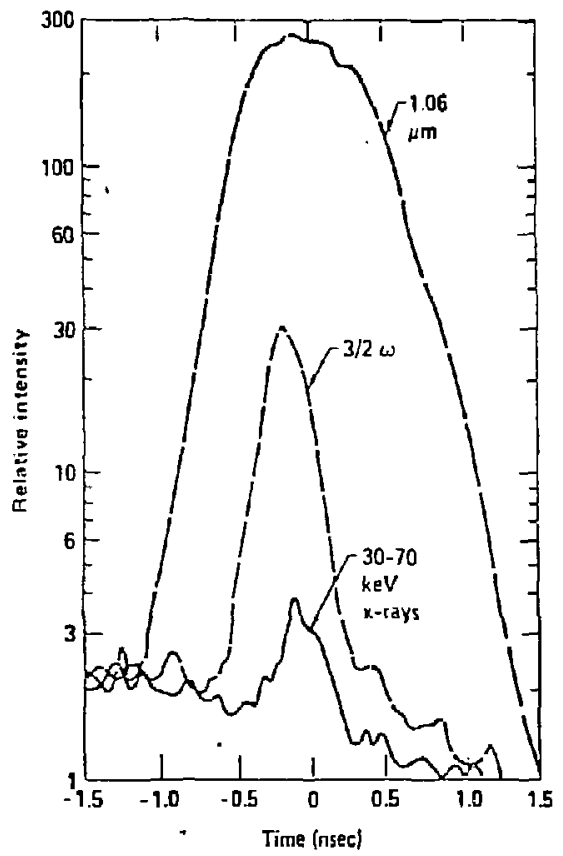

Fig. 9. Time history of the $1 w_{0}$ incident pulse, the $3 / 2 w_{0}$ light, and the $30-70 \mathrm{keV} x$-rays fom the thin foil experiment described in Fig. $7 a$. 
The time and source integrated $x$-ray spectrum from this experiment is shown in Fig. 10.. The hard $x$-ray "tail with a slope $>40 \mathrm{keV}$ shows that high-energy electron distributions can be produced by these instabilities. Also shown in the figure is a LASNEX prediction using a resonance absorption model only. The low cemperature distribution is due to the fact that the foil goes underdense $\left(n_{e}<n_{c}\right)$ early in the pulse. However, even if resonance absorption vere operative over the entire laser pulse, temperatures of only $13-20 \mathrm{keV}$ would be expected for this peak intensity. (The calculated $x-r$ ay $y$ ields are not meaningful, since the simulation does not include fast electron transport co the Au washer, ]

Evidence for anorymously high $x$-ray spectra have also been obtained in moderate intensity, long-pulse experiments. (13) In Fig. 11 we show the $x$-ray spectra from thick carbon targets irradiated with 3 nsec pulses in a $1 \mathrm{~mm}$ focal spot at a peak intensity of $21 \times 10^{14} \mathrm{~W} / \mathrm{cm}^{2}$. The $8 \mathrm{keV} \times$-ray spectra is again to be contrasted with the simulation which only includes resonance absorption. - The $x$ ray spectrum and optical pyrometry of the rear surface of the Earget implied that approximately 30 of the incident laser energy was contained in an $8 \mathrm{keV}$ suprathemal electron distribution. (i 3 ) The large efficiency in $3 / 2$ wo light generation (see Table 1) ehreshold

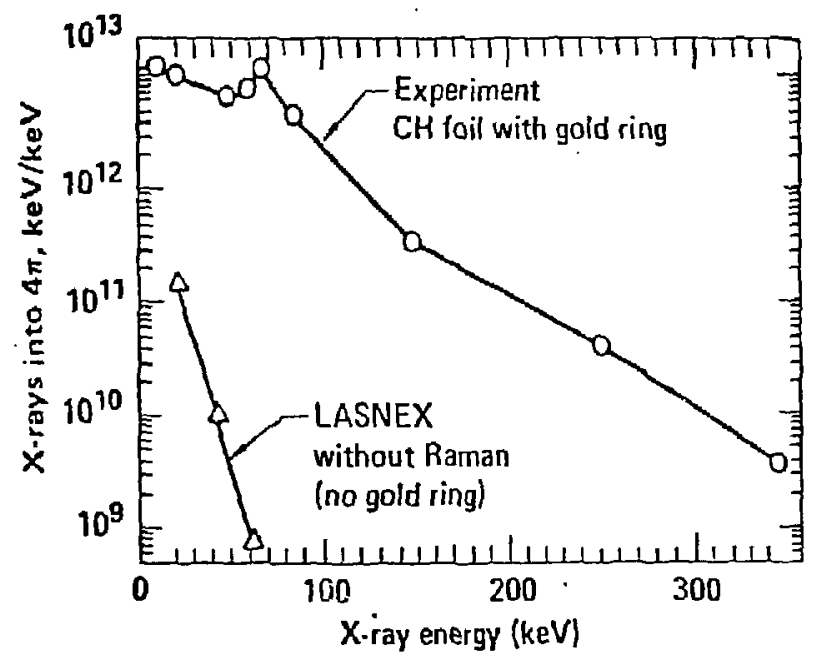

Fip. 10. Time-integrated, high-energy $x$-ray spectra obtained from thin foil experiment described in Fig. 7a, compared to LASNEX prediction, using resonance absorption only. 


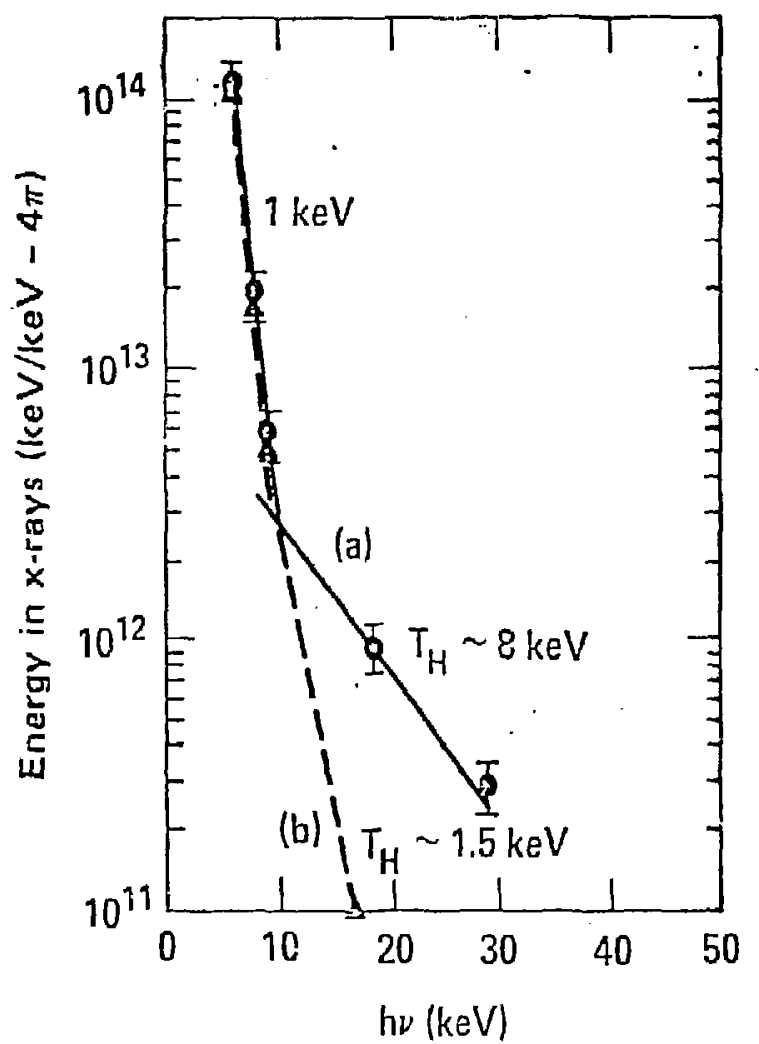

Fig. 11. High-energy $x-r a y ~ s p e c t r a$ from a carbon plasma irradiated by a $1 \times 10^{-4} \mathrm{~W} / \mathrm{cm}^{2}, 3 \mathrm{nsec}$ pulse onto a $1 \mathrm{~mm}$ focal spot. Also shown in a LASNEX prediction using a resonance absorption model only.

arguments and the timing of the electron generated preheat support the $2 \omega_{\text {pe }}$ instability as the source of the fast electrons in these experiments.

\section{SU NARY AND CONCLUSIONS}

In this paper, we have presented some experimental results which shed light on the coupling physics of long-scale length plasmas with $1.064 \mu \mathrm{m}$ irradiation. Brillouin Scattering, in competition with inverse bremsstrahlung, appears to play an influential role in target absorption for even moderate values of $I \lambda_{0}^{2}$ of $21 \times 10^{14} \mathrm{~W} / \mathrm{cm}^{2}-\mu \mathrm{m}^{2}$. In addition, when the laser spot is made large 
enough to maintain a near $1-D$ expansion, sidescatter tather than backscatter dominates." Enhanced noise säurces, such as specular reflection from $n_{c}$, are not required to produce large-angle Brillouin Scattering. (it)

Additional experiments have shown that scattered 1 ight signatures of Stimulated Raman and the two-plasmon iecay instabilicies are strongly dependent on both the intensity and size of the underdense plasma. In exploding foil experiments, SRS efficiencies as large as $20 \%$ have been observed. Furthermore, in these experiments the presence of fast electrons created by the damping of electron plasma waves near $n_{c} / 4$ has been directly rbserved by the simultaneous recording of both the $3 / 2 w_{0}$ harmonic light and the $30-70 \mathrm{keV}$ $x$-rays. Time and space integrated g-ray spectra have also shown anomalously hot (i.e. in excess of that produced by resonance absorption) electron populations that we ascribe to either the twoplasmon or Raman instabilities. Hot electron temperatures in excess of $40 \mathrm{keV}$ have been measured.

While we have concentrated on the Brillouin, Raman, and twoplasmon decay instabilities, many other processes, notably filamentation (thermal or pondermotive) can also occur in large plasmas and indeed may be influencing the results discussed in this paper. (5) It should be clear from this discussion that extreme caution must be exercised in the extrapolation of the results of present short wavelength studies ro future target experiments. Definitive experiments on the wavelength scaling of interaction physics awaits the arrival of larger laser systems (i.e. NOVETTE) or the exploitation of clever experimental techniques.

\section{REFERENCES}

1. E. Fabre, F. Ameranoff, R. Fabbro, C. Garbon-Labasine, J. Vermont, M. Neingeld, F. David, R. Pellat, Plasma Physics and Controlied Nuclear Fusion Research (IAEA, Vienna, 1980) Vol. II-IAEA-CN-38/I-4; E. M. Campbe11, V. C. Rupert, W. C. Mead, R. E. Turner, C. E. Max, K. G. Estabrook, F. 2e, 14th ECLM, Palaiseau, France, 1980; D. C. Slater, G. E. Busch, G. Charatis, R. R. Johnson, F. J. Mayer, R. J. Schroeder, J. D. Simpson, D. Sullivan, J. A. Tarvin, C. E. Thomas, Physical Review Letters 46:1199; B. Yaakobi, T. Boehly, P. Bourke, Y. Conturie, R. I. Craxton, J. Delettrez, J. M. Forsyth, R. D. Frankel, L. M. Goldman, R. L. MeCrory, M. C. Richardson, W. Seka, D. Shivarts, and J. M. Soures, Characteristics of Target Interaction with High Power UV Laser Radiation, Opt. Comm. $39: 175-179(1981)$.

2. C. E. Max and K. G. Estabrook, Comnents on Piasma Physics and Controlled Fosion 5:239 (1980). 
3. S. E. Bodner, NRL Memorandum Report 4453: (January 21, 1981).

4. W. L. Kruer, Comments Plasma Physics Controlled Fusion Yol. 6, No. 5:167-175 (1981); B. F. Lasinski, A. B. Langdon, K. G. Estabrook, H. L. Kruer, UCRL-50021-80:3-31, LLNL Laser Annual Report: (1980).

5. C. E. Max, E. M. Cempbell, W. C. Mead, H. L. Kruer, D. W. Phillion, R. E. Turner, B. F. Lasinski, and K. G. Estabrook, 6th Workshop on Laser Interaction with Matter, Monterey: (1981), published this volume.

6. R. E. Turner, D. W. Phillion, E. M. Campbell, K. G. Estabrook, to be published in Phys. Fluids: (February, 1983); K. Tanaka,

L. M. Goldman, H. Seka, M. C. Richardson, J. M. Soures,

E. A. Williams, Phys. Rev. Lett. 48:17 (April 26, 1982).

7. D. R. Speck, J. Glaze, W. L. Simmons, J. Hunt, J. Holzrichter, IEEE J. Quantum Electron. 17:1599 (1981).

8. K. G. Estabrook, E. J. Valeo, W. L. Kruer, Phys. Fluids 18:1151 (1975).

9. K. R. Manes, V. C. Rupert, J. M. Auerbach, P. Lee, J. E. Swain, phys. Rev. Lett. 39:281 (1977); A. G. M. Mazswinkel, K. Eidmann, R. Sige1, Phys. Rev. Lett. 42:1625 (1979).

10. P. Mora, Phys. Fluids 25:6 (June 1982).

11. G. B. Zimmle rman, UCRL-74811(1973); G. B. $\cdots . . .$, and h. L. Kruer, Controlled Plasma Physics 2:85 (1975).

12. M. D. Rosen, D. W. Phillion, v. C. Rupert, W. C. Mead, W. L. Kruer, J. J. Thomson, H. W. Kornblum, V. W. Slivinsky, G. J. Caporaso, M. J. Boyle, K. G. Tirsell, Fnys. Fluids 22:10 (October, 1979); K. Tanaka, L. M. Goldman, Phys. Rev. Lett. 45:1558 (I g80).

13. E. M. Campbell, M. D. Rosen, D. W. Phillion, R. H. Price, K. G. Estabrook, B. F. Lasinski, S. O. Obenschain, E. A. McLean, R. R. Whitlock, B. H. Ripin, Laser Plasma Coupling in Long Pulse, Long Scale Length Plasmas, App. Phys. Lett.: (to be published).

14. P. D. Carter, S. M. L. Sim, H. C. Barr, R. G. Evans, Phys. Rev. Lett. 44:1407(1980); J. Rizzo, S. A. Letzring, M. C. Richardson, R. S. Crarton, Bull. American. Phys. Soc. 27:909 (1982); A. I. Avrov, Sov. Phys. JETP 45:507 (1977). 
15. D. W. Phillion, D. L. Banner, E. M. Campbell, R. E. Iurner, R. G. Estabrook, Phys. Fluids 25:8 (August, 1982).

16. D. W. Phillion, E.'M. Campbell, K. G. Estabrook, F. Ze, G. Phillips, R. L. Leche, Phys. Rev. Lett. 49:1405 (1982).

17. G. R. Mitchel, B. Grek, T. W. Johnston, H. Pepin, P. Church, P. Lavigne, F. Martin, R. Dicoste, Phys. Rev. Lett. 4B:21 (May 24, 1982).

\author{
BISCI.ABMER
}

This ducument was prepared us an arcount of work uponsored bs an agence of the linited States Governutent. Neither the I! nited States Gevernment nor the University of California nor any of their employece, makes any warranty, ex. press or implied, or asoumes any legal liability or responsibility for the accuracy. completeness, or usefuloses of any information, apparatus, product. or process diselosed, or represents that is use would not iniringe privately ow ned rights. Reference herein fo any specific commercisl products, process, or service by trade name, trademark, manulacturer, or otherujiss, does not neescsarily constitute or imply its endarsement, recammendation, or lavoring by the L'nited States Government or the Liniversily of California. The views and upinions of authors expressed herein do nat nesessarily state or reflest thass of the I nited Stales Govemment thereof, and shall not be used for advertising or product endorsement purposes. 